\title{
RESPOSTA DA GRAMA ESMERALDA EM FUNÇÃO DE DIFERENTES FERTILIZANTES E SUBSTRATOS
}

\author{
Patrick Luan Ferreira dos Santos ${ }^{1 *}$, Regina Maria Monteiro de Castilho ${ }^{2}$
}

\footnotetext{
${ }^{1}$ Doutorando em Agronomia (Horticultura), Universidade Estadual Paulista (UNESP), Faculdade de Ciências Agronômicas (FCA), Botucatu - SP. *E-mail: patricklfsantos@gmail.com

${ }^{2}$ Professora Assistente Doutora, Departamento de Fitotecnia, Tecnologia de Alimentos e Sócio Economia, Universidade Estadual Paulista (UNESP), Faculdade de Engenharia de Ilha Solteira, Ilha Solteira - SP.
}

\section{Recebido: 03/02/2018; Aceito: 07/06/2018}

RESUMO: A grama esmeralda necessita de todos os macro e micronutrientes essenciais para seu bom desenvolvimento, contudo não existem recomendações oficiais de adubação para a espécie e ainda, para melhor aproveitamento dos mesmos, ela deve ser instalada em substratos adequados. Assim o presente trabalho teve como objetivo analisar a resposta da grama esmeralda em função de diferentes fertilizantes e substratos. $\mathrm{O}$ experimento foi desenvolvido na UNESP-Ilha Solteira/SP, sendo utilizados cinco substratos: S1- solo; S2solo + areia (2:1); S3- solo + composto orgânico (1:1); S4- solo + composto orgânico + areia (2:1:1); S5- composto orgânico + areia (3:1), instalados em contêineres de 8,46 L, e posteriormente implantada a grama esmeralda sobre cada substrato. As adubações realizadas foram: $60 \mathrm{~g} \mathrm{~m}^{-2}$ de NPK (10-10-10) e $125 \mathrm{~g} \mathrm{~m}^{-2}$ de Forth Jardim ${ }^{\circledR}$, sendo mantido um tratamento sem adubação (testemunha). Realizou-se análises do teor de clorofila das folhas, massa fresca e seca da parte aérea. Foi observado que houve resposta da grama esmeralda em função dos fertilizantes e substratos, sendo que S5 adubado com NPK apresentou maiores valores de clorofila $(20,81 \mathrm{CCI})$, e quando adubado com Forth Jardim ${ }^{\circledR}$ constatou maior massa fresca e seca $\left(1,47\right.$ e $0,74 \mathrm{~kg} \mathrm{~m}^{-2}$ respectivamente), contudo, maior massa produzida implica em maiores gastos de corte de manutenção do gramado. Conclui-se ainda que as adubações realizadas com NPK e Forth Jardim $^{\circledR}$ proporcionaram resultados superiores a testemunha, mostrando a importância da adubação para manutenção para a estética da grama esmeralda.

Palavras-chave: NPK. Forth Jardim ${ }^{\circledR}$. Zoysia japonica. Gramado ornamental.

\section{RESPONSE OF THE EMERALD GRASS IN THE FUNCTION OF DIFFERENT FERTILIZERS AND SUBSTRATES}

\begin{abstract}
The emerald grass needs all the macro and micronutrients essential for its good development. However, there are no official fertilization recommendations for the species and, for better use, it must be installed on suitable substrates. Thus, the present work had as objective to analyze the response of the emerald grass in function of different fertilizers and substrates. The experiment was developed at UNESP-Ilha Solteira/SP, using five substrates: S1- soil; S2- soil + sand (2:1); S3- soil + organic compound (1:1); S4- soil +
\end{abstract}


organic compost + sand $(2: 1: 1)$; S5- organic compost + sand $(3: 1)$, installed in $8.46 \mathrm{~L}$ containers, and then implanted the emerald grass on each substrate. The fertilizations were: $60 \mathrm{~g} \mathrm{~m}^{-2}$ of NPK (10-10-10) and $125 \mathrm{~g} \mathrm{~m}^{-2}$ of Forth Jardim ${ }^{\circledR}$, being maintained a treatment without fertilization (control). Were carried out analyzes of leaf chlorophyll content, fresh and dry shoot mass. It was observed that there was a response of emerald grass as a function of fertilizers and substrates, and S5 fertilized with NPK presented higher values of chlorophyll (20.81 CCI), and when fertilized with Forth Jardim ${ }^{\circledR}$, it was observed a higher fresh and dry mass (1.47 and $0.74 \mathrm{~kg} \mathrm{~m}^{-2}$, respectively), however, the higher mass produced implies higher turfgrass maintenance cut costs. It was also concluded that the fertilizations performed with NPK and Forth Jardim $^{\circledR}$ provided superior results to the control, showing the importance of maintenance fertilization for the aesthetics of the emerald grass.

Key words: NPK. Forth Jardim ${ }^{\circledR}$. Zoysia japonica. Ornamental turfgrass.

\section{INTRODUÇÃO}

Os gramados têm assumido lugar de destaque tanto pelo seu admirável valor estético como por suas diversas funcionalidades (CARRIBEIRO, 2010). Segundo Zanon (2015), o setor produtivo de gramas cultivadas teve seu melhor momento na última década, e dentre os fatores que propiciaram este resultado, destaca-se a atuação do Ministério da Agricultura, Pecuária e Abastecimento (MAPA) que, visando combater o extrativismo da grama-batatais (Paspalum notatum), regulamentou a produção comercial o que proporcionou um aumento no volume produzido pelo setor.

Godoy et al. (2012b) ressaltam que, junto a esse crescimento, uma espécie que vem se destacando é a grama-esmeralda (Zoysia japonica). Originária da Ásia é uma gramínea herbácea rizomatosa-estolonífera, perene e muito ramificada. A espécie possui folhas estreitas e pequenas, dispostas em hastes curtas e densas, formando um perfeito tapete (LORENZI, 2015). O principal objetivo em sua utilização é o aspecto estético (visual), ou seja, gramados com boa densidade e de coloração verde intensa (LIMA et al., 2012).

Assim, áreas gramadas, como qualquer outra cultura, necessitam de nutrientes em qualidade e quantidades essenciais para expressarem sua exuberância e completarem seu desenvolvimento (LIMA et al., 2015). No Estado de São Paulo não há recomendação oficial de adubação para implantação e manutenção de gramados, o que acaba dificultando a nutrição das espécies de grama com fertilizações errôneas (GODOY et al., (2012a).

Outro fator que restringe o desenvolvimento de gramados é o substrato onde as espécies são instaladas (KUHN, 2015). Segundo Aldahir (2012), estão sendo conduzidos diversas pesquisas, visando o melhor tipo de substrato para instalação de gramados, tendo como base, componentes de solo, areia e composto orgânico. Todavia, as informações ainda são incipientes e são necessários estudos para diminuir essa situação. Dessa forma o trabalho teve como objetivo analisar a resposta da grama esmeralda em função de diferentes fertilizantes e substratos. 


\section{MATERIAL E MÉTODOS}

O ensaio foi conduzido em contêineres de plástico preto, mantidos a pleno sol na Faculdade de Engenharia de Ilha Solteira - UNESP, Campus-II, na cidade de Ilha Solteira/SP, com latitude $20^{\circ} 22^{\prime}$ 'S, longitude $51^{\circ} 22^{\prime}$ WGR e altitude média de $335 \mathrm{~m}$. No período de avaliação a temperatura média foi de $27,6{ }^{\circ} \mathrm{C}$, com umidade relativa média de 68,7\% (DADOS CLIMÁTICOS - ILHA SOLTEIRA, 2012).

O experimento foi implantado no dia 15 de setembro de 2012, realizado em esquema fatorial $5 \times 3$ [5 substratos $\mathrm{x}$ (2 fertilizantes + testemunha)], sendo o delineamento experimental utilizado inteiramente casualisado com 15 tratamentos e 3 repetições cada. Os substratos foram: $\mathrm{S} 1$ = solo, $\mathrm{S} 2$ = solo + areia (2:1), S3 = solo + composto orgânico (1:1), $\mathrm{S} 4=$ solo + composto orgânico + areia $(2: 1: 1)$ e S5 = composto + areia $(3: 1)$, e os fertilizantes foram: $60 \mathrm{~g} \mathrm{~m}^{-2}$ de NPK (10-10-10) e $125 \mathrm{~g} \mathrm{~m}^{-2}$ de Forth Jardim ${ }^{\circledR}$ segundo a recomendação do fabricante (os dados de formulação do Forth Jardim ${ }^{\circledR}$ constam da Tabela 1) e a testemunha (sem adubação).

Para a instalação do experimento, foram utilizados tapetes de grama-esmeralda de dimensão $0,62 \times 0,45 \mathrm{~m}$, sendo esses recortados e implantados em contêineres de plástico preto $(47,5 \times 17,5 \mathrm{~cm}$ medidas superiores, 41,5 x 11,3 cm medidas inferiores, altura 15,5 $\mathrm{cm}$, volume 8,46 litros) com os substratos já preparados e alocados dentro de cada contêiner, previamente identificados. A primeira adubação foi realizada em seguida, com Forth Jardim $^{\circledR}$ e NPK (10-10-10), sendo que ambos foram espalhados sobre o gramado, devidamente identificados e regados em seguida. A segunda adubação foi realizada no dia 22 de dezembro de 2012, utilizando-se do mesmo procedimento.

Tabela 1. Dados da formulação do adubo Forth Jardim ${ }^{\circledR}$, segundo o fabricante.

\begin{tabular}{ccccccccccccc}
\hline & $\mathrm{N}$ & $\mathrm{Ca}$ & $\mathrm{B}$ & $\mathrm{Fe}$ & $\mathrm{P}_{2} \mathrm{O}_{5}{ }^{*}$ & $\mathrm{Mg}$ & $\mathrm{Mo}$ & $\mathrm{Cu}$ & $\mathrm{K}_{2} \mathrm{O}^{* *}$ & $\mathrm{~S}$ & $\mathrm{Mn}$ & $\mathrm{Zn}$ \\
\hline$\%$ & 13,0 & 1,0 & 0,04 & 0,2 & 5,0 & 1,0 & 0,005 & 0,05 & 13,0 & 5,0 & 0,08 & 0,15 \\
\hline
\end{tabular}

*Solúvel em CNA + água; **Solúvel em água.

Para preparação dos substratos, o solo utilizado foi um Latossolo Vermelho Distroférrico (EMBRAPA, 2006) retirado da camada de $0-20 \mathrm{~cm}$, sob cerrado, em área de reserva legal da FEPE (Fazenda de Ensino, Pesquisa e Extensão) da Faculdade de Engenharia - UNESP/Campus de Ilha Solteira, localizada no município de Selvíria - MS. O composto orgânico foi decomposto por um ano, sendo formado das folhas de grama batatais e esterco de curral (1:1) e a areia média lavada foi adquirida no comércio local. O controle de plantas daninhas foi realizado sempre que necessário, através da retirada manual das ervas. Já o manejo da irrigação foi realizado diariamente de forma manual, sendo que os contêineres receberam água até a saturação, a fim de garantir que o fator água não interferisse nos resultados do experimento.

Para avaliação do desenvolvimento do gramado, foi medido o teor de clorofila das folhas - obtido com o auxílio do clorofilômetro manual Chlorophyll Content Meter (CCM 200) da marca Opti-sciences, cuja unidade de medida é CCI (Chlorophyll Content Index) 
que apresenta o valor proporcional à quantidade de clorofila da amostra. O aparelho apresenta precisão de +/- 1 CCI e o parâmetro de mensuração utilizado é a absorbância ótica de dois comprimentos de onda (OPTI_SCIENCES, 2018). As avaliações foram realizadas nos dias 15, 23 e 30 de setembro, 7, 13 e 28 de outubro, 18 novembro, 2, 9 e 21 de dezembro de 2012, 20 e 27 de janeiro, 10, 17 e 24 de fevereiro, 3, 10 e 24 de março de 2013, sendo coletadas de 4 a 6 folhas de grama-esmeralda de cada contêiner, estas foram dispostas no clorofilômetro de modo a cobrir inteiramente o detector, sem que as folhas fossem sobrepostas.

Ainda, foram avaliadas a massa fresca e massa seca das folhas, sendo coletadas toda a parte aérea do gramado de cada contêiner, e foram armazenadas em sacos de papel previamente tarados e identificados, em seguida, determinada a massa fresca, sendo a massa seca mensurada após alocação das amostras em estufa, a $60^{\circ} \mathrm{C}$, e pesadas depois de 3 dias, quando estabilizada a massa. Todas as pesagens foram realizadas em balança de $0,01 \mathrm{~g}$ de precisão, e os resultados expressos em $\mathrm{kg} \mathrm{m}^{-2}$, sendo realizadas três coletas: 13 de outubro, 22 de dezembro de 2012 e 24 de março de 2013.

Os resultados das avaliações foram submetidos através de análise de variância $\mathrm{F}$ e teste de Tukey ao nível de 5\% de probabilidade para comparação de médias, utilizando-se do programa SISVAR para análise dos dados (FERREIRA, 2014).

\section{RESULTADOS E DISCUSSÃO}

A Tabela 2 apresenta os resultados dos teores médios de clorofila das folhas de grama esmeralda, em função de diferentes fertilizantes e substratos.

Tabela 2. Média do Teor de clorofila das folhas de grama esmeralda cultivada em diferentes substratos e fertilizantes.

\begin{tabular}{|c|c|c|c|}
\hline \multirow{2}{*}{ Substratos } & \multicolumn{3}{|c|}{ Teor de Clorofila (CCI) } \\
\hline & Testemunha (sem adubação) & NPK (10-10-10) & Forth Jardim $^{\circledR}$ \\
\hline S1-S & $11,62 \mathrm{bB}$ & $17,53 \mathrm{bA}$ & $17,45 \mathrm{abA}$ \\
\hline S2- S+A 2:1 & $10,52 \mathrm{bB}$ & $17,44 \mathrm{bA}$ & $16,86 \mathrm{bA}$ \\
\hline S3- S+CO 1:1 & $15,99 \mathrm{aB}$ & $19,83 \mathrm{abA}$ & $19,43 \mathrm{abA}$ \\
\hline $\mathrm{S} 4-\mathrm{S}+\mathrm{CO}+\mathrm{A} 2: 1: 1$ & $16,45 \mathrm{aB}$ & $19,84 \mathrm{abA}$ & $19,04 \mathrm{abA}$ \\
\hline S5- CO+A 3:1 & $17,82 \mathrm{aB}$ & $20,81 \mathrm{aA}$ & $20,00 \mathrm{aAB}$ \\
\hline DMS linha $(5 \%)$ & \multicolumn{3}{|c|}{2,37} \\
\hline DMS coluna $(5 \%)$ & \multicolumn{3}{|c|}{2,78} \\
\hline $\mathrm{CV}(\%)$ & \multicolumn{3}{|c|}{6,76} \\
\hline F subst. x (fertil. + test.) & \multicolumn{3}{|c|}{$2,386^{*}$} \\
\hline
\end{tabular}

Médias seguidas de mesma letra minúscula na coluna, e mesma letra maiúscula na linha não diferem entre si ao nível de 5\% de significância pelo teste Tukey. ns- não significativo; $*_{\text {- }}$ significativo a $5 \%$ pelo teste $\mathrm{F}$; **significativo a $1 \%$ pelo teste F. S - Solo; A - Areia; CO - Composto Orgânico (1:1).

Pode-se observar, que o substrato S5 provido de composto orgânico + areia (3:1) adubado com NPK (10-10-10) apresentou a maior média numérica (20,81 CCI), sendo esta 
estatisticamente igual aos tratamentos S3 e S4 adubados com o mesmo fertilizante. Observase ainda em S5 quando comparando os dois fertilizantes (NPK e Forth Jardim®) não existe diferença estatística entre eles, entretanto NPK (10-10-10) se difere da testemunha.

O substrato 2 (solo + areia 2:1) sem adubação (testemunha) foi o que apresentou menor resultado do teor de clorofila $(10,52 \mathrm{CCI})$, sendo que este apresentou diferença significativa quando comparado a NPK e Forth Jardim ${ }^{\circledR}$, e quando comparado com os demais substratos, apenas S1 é estatisticamente igual. Fato esse, se deve, pois, os substratos S1 e S2 não são a base de composto orgânico, e segundo Kämpf (2005), quando não se tem adição de matéria orgânica em substratos, ocorre menor capacidade de retenção de água, baixos valores de CTC e consequentemente disponibilidade de nutrientes, o que reflete em menores valores de clorofila. Pontel et al. (2011) em trabalho com índice de clorofila em grama esmeralda sob condições de estresse hídrico, observaram que os substratos providos de matéria orgânica apresentaram intervalos entre 4,5 a 15,2 CCI e os que não continham o composto, houve morte das plantas.

O efeito benéfico do composto orgânico também foi confirmado por Dias et al. (2015) avaliando grama São Carlos em substratos e fertilizantes, onde os tratamentos à base de matéria orgânica juntamente com os adubos Forth Jardim ${ }^{\circledR}$ e NPK (10-10-10) apresentaram os melhores resultados do teor de clorofila das folhas, fato esse também foi observado neste trabalho (Tabela 2).

Os resultados encontrados no presente estudo estão dentro do intervalo (4,5-28,90 CCI) observado por Santos et al. (2016) em trabalho com diferentes substratos no desenvolvimento de grama esmeralda. E semelhantes aos constatados por Dinalli et al. (2012) também com a mesma espécie (14,7-21,3 CCI). Amaral e Castilho (2012) em experimento com diferentes fertilizantes em grama batatais, observaram resultados variando de 16,84 até 37,77 CCI, índices altos quando comparados aos do presente trabalho.

Os valores encontrados do teor de clorofila das folhas refletem indiretamente as concentrações de $\mathrm{N}$ do tecido vegetal, devido provavelmente as clorofilas serem moléculas formadas por complexos derivados da porfirina, tendo como átomo central o magnésio, ligado a 4 outros de nitrogênio (TAIZ e ZEIGER, 2017). Ainda, segundo Marenco e Lopes (2007), 50 a $70 \%$ do $\mathrm{N}$ total das folhas são integrantes de enzimas que estão associadas aos cloroplastos. Experimentos entre relação de índice do conteúdo de clorofila e nitrogênio foliar em grama esmeralda corroboram com o citado e foram evidenciados por Dinalli et al. (2016), Santos e Castilho (2015) e Oliveira et al. (2018).

Observa-se ainda que todos os substratos adubados com NPK diferem da testemunha (sem adubação), já nos substratos adubados com Forth Jardim® apenas em S5, foi estatisticamente igual à testemunha, assim, pode-se dizer que independente do substrato, não existe diferente entre as adubações realizadas com NPK e Forth Jardim ${ }^{\circledR}$. Entretanto, as quantidades de nutrientes presentes nos dois fertilizantes são distintas, enquanto NPK apresenta $10 \%$ de Nitrogênio, $10 \%$ de Fósforo e $10 \%$ de Potássio, Forth Jardim ${ }^{\circledR}$ contém, $13 \%, 5 \%$ e $13 \%$ dos mesmos elementos respectivamente, além de outros (Tabela 1). Assim, 
infere-se que o fabricante poderia diminuir a quantidade de $\mathrm{N}$ e $\mathrm{K}$ de seu produto, sem prejudicar a qualidade estética do gramado. Contudo, os resultados obtidos no presente trabalho, podem ser considerados baixos, pois Lima (2009), em trabalho com diferentes doses de fonte de nitrogênio em grama esmeralda, verificaram aumento nas leituras em clorofilômetro conforme aumento dos teores de nitrogênio, conferindo maior intensidade de cor verde e maiores concentrações de $\mathrm{N}$, e observaram um intervalo de 36,5 a 39,2 CCI, e no presente trabalho, nenhum dos tratamentos atingiu o referido valor.

Verifica-se que os substratos a base de composto orgânico em sua composição apresentaram os maiores valores do teor de clorofila. Segundo Santos e Castilho (2016) substratos compostos de matéria orgânica possuem maior capacidade de retenção de nutrientes, e como consequência apresentam respostas fisiológicas positivas, sendo o teor de clorofila uma delas.

Santos et al. (2016), avaliando a influência de diferentes substratos no teor de clorofila das folhas de grama esmeralda, encontraram intervalos entre 13,09 a 18,18 CCI, e observaram que os substratos que continham matéria orgânica em sua composição apresentaram os melhores resultados, fato esse condizente com o presente estudo. Castilho et al. (2012) verificaram que o índice de clorofila das folhas de grama esmeralda foi influenciado pelo substrato, encontrando intervalos entre 8,33 a 14,70 CCI.

A tabela 3 apresenta os valores médios de massa fresca das folhas de grama esmeralda, em função de diferentes fertilizantes e substratos.

Tabela 3. Média da massa fresca das folhas de grama esmeralda cultivada em diferentes substratos e fertilizantes.

\begin{tabular}{lccc}
\hline \multirow{2}{*}{ Substratos } & \multicolumn{3}{c}{ Massa Fresca $\left(\mathrm{kg} \mathrm{m}^{-2}\right)$} \\
\cline { 2 - 4 } & Testemunha (sem adubação) & NPK $(10-10-10)$ & Forth Jardim $^{\circledR}$ \\
\hline S1- S & $0,49 \mathrm{bA}$ & $0,65 \mathrm{bA}$ & $0,78 \mathrm{cA}$ \\
S2- S+A 2:1 & $0,41 \mathrm{bB}$ & $0,56 \mathrm{bB}$ & $0,99 \mathrm{bcA}$ \\
S3- S+CO 1:1 & $0,83 \mathrm{abB}$ & $1,21 \mathrm{aA}$ & $1,23 \mathrm{abA}$ \\
S4- S+CO+A 2:1:1 & $0,50 \mathrm{bB}$ & $0,80 \mathrm{abAB}$ & $1,10 \mathrm{abcA}$ \\
S5- CO+A 3:1 & $1,04 \mathrm{aB}$ & $1,21 \mathrm{aAB}$ & $1,47 \mathrm{aA}$ \\
\hline DMS linha (5\%) & \multicolumn{4}{c}{0,37} \\
DMS coluna (5\%) & \multicolumn{4}{c}{0,43} \\
CV (\%) & \multicolumn{4}{c}{$0,802^{\text {ns }}$} \\
F subst. x (fertil. + test.)
\end{tabular}

Médias seguidas de mesma letra minúscula na coluna, e mesma letra maiúscula na linha não diferem entre si

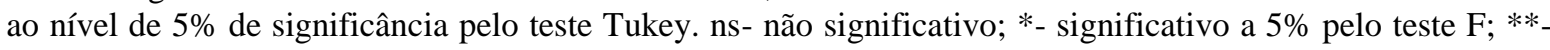
significativo a 1\% pelo teste F. S - Solo; A - Areia; CO - Composto Orgânico (1:1).

Nota-se na Tabela 3 que o tratamento que apresentou maior valor de massa fresca foi S5 adubado com Forth $\operatorname{Jardim}^{\circledR}\left(1,47 \mathrm{~kg} \mathrm{~m}^{-2}\right)$, sendo que este difere apenas de S1 e S2 adubado com o mesmo fertilizante, e da Testemunha (sem adubação). Já o substrato 2 sem adubação, apresentou menor média $\left(0,41 \mathrm{~kg} \mathrm{~m}^{-2}\right)$, no entanto, ele difere estatisticamente apenas de S5 sem adubação e de S2 adubado com Forth Jardim ${ }^{\circledR}$. 
Sampaio (2012) destaca que o corte de manutenção do gramado é de fundamental importância para o desenvolvimento uniforme da planta, sendo que cada espécie tem necessidades de alturas de cortes diferentes. O autor recomenda para grama esmeralda cortes de 2-4 cm da parte aérea, contudo, esse corte depende da altura que se encontra o gramado, e quando adubado com fertilizantes a base de nitrogênio em sua composição, seu crescimento é acelerado, e assim, o gramado produz maior massa fresca (GAZOLA, 2017). Dessa forma, para Santos et al. (2016) quanto maior a quantidade de massa fresca produzida, maior o custo para manter a estética do gramado, e consequentemente, há maior gasto com máquinas, operadores e combustível, além do que, quando a dose de $\mathrm{N}$ for aplicada em excesso podem haver perdas econômicas relacionadas ao desperdício do adubo (OLIVEIRA et al., 2015). Assim, infere-se que a máquina de corte terá que operar com maior frequência em S5 adubado com Forth Jardim ${ }^{\circledR}$ do que nos demais tratamentos.

Contudo, estatisticamente, é observado diferença entre os fertilizantes NPK e Forth Jardim $^{\circledR}$, apenas nas adubações realizadas no substrato 2, nos demais substratos, as duas adubações não se diferem. Assim, S5 adubado com NPK, que apresentou o melhor resultado do teor de clorofila (Tabela 2), proporcionou o segundo maior valor de massa fresca (Tabela 3 ), diminuindo uma quantidade de $0,26 \mathrm{~kg} \mathrm{~m}^{-2}$, o que é desejável para o desenvolvimento de um gramado ornamental, ou seja, alta coloração verde, e considerável quantidade de massa fresca produzida, o que acarreta em diminuição de custo.

Tabela 4. Média da massa seca das folhas de grama esmeralda cultivada em diferentes substratos e fertilizantes.

\begin{tabular}{lccc}
\hline \multirow{2}{*}{ Substratos } & \multicolumn{3}{c}{ Massa Seca $\left(\mathrm{kg} \mathrm{m}^{-2}\right)$} \\
\cline { 2 - 4 } S1- S & Testemunha (sem adubação) & NPK $(10-10-10)$ & Forth Jardim $^{\circledR}$ \\
S2- S+A 2:1 & $0,22 \mathrm{bB}$ & $0,32 \mathrm{bAB}$ & $0,43 \mathrm{cA}$ \\
S3- S+CO 1:1 & $0,27 \mathrm{bB}$ & $0,51 \mathrm{bcA}$ \\
S4- S+CO+A 2:1:1 & $0,40 \mathrm{abB}$ & $0,58 \mathrm{aA}$ & $0,66 \mathrm{abA}$ \\
S5- CO+A 3:1 & $0,25 \mathrm{bB}$ & $0,38 \mathrm{abAB}$ & $0,55 \mathrm{abcA}$ \\
DMS linha (5\%) & $0,50 \mathrm{aB}$ & $0,56 \mathrm{aB}$ & $0,74 \mathrm{aA}$ \\
DMS coluna (5\%) & \multicolumn{5}{c}{0,17} \\
\hline CV (\%) & 0,21 \\
F subst. x (fertil. + test.) & \multicolumn{3}{c}{19,60} \\
\hline
\end{tabular}

Médias seguidas de mesma letra minúscula na coluna, e mesma letra maiúscula na linha não diferem entre si ao nível de 5\% de significância pelo teste Tukey. ns- não significativo; *- significativo a 5\% pelo teste $\mathrm{F}$; **significativo a $1 \%$ pelo teste F. S - Solo; A - Areia; CO - Composto Orgânico (1:1).

Os valores de massa fresca, após secagem, diminuem por conta da perda de água, contudo, o custo de manutenção, se mantém, ou seja, quanto maior a quantidade de matéria seca produzida, maior a necessidade de cortes para a manutenção de sua estética (AMARAL e CASTILHO, 2012). E esses resultados da massa seca da parte aérea da grama esmeralda, são evidenciados na Tabela 4. 
Observa-se que assim, como a massa fresca, o maior resultado foi observado por S5 adubado com Forth Jardim ${ }^{\circledR}$, sendo que ele se difere apenas de S1 e S2 adubado com Forth Jardim $^{\circledR}$, e também é diferente estatisticamente do mesmo substrato adubado com NPK e do Tratamento sem adubação (Testemunha).

Santos et al. (2016) trabalhando com diferentes substratos no desenvolvimento da grama esmeralda, encontraram intervalos de 1,09 a $2,4 \mathrm{~kg} \mathrm{~m}^{-2}$ para massa fresca, e 0,45 a $0,84 \mathrm{~kg} \mathrm{~m}^{-2}$ para massa seca, e observaram que os maiores resultados foram obtidos pelos substratos que continham matéria orgânica em sua composição, e concluíram que quanto maior o valor, mais gasto para corte de manutenção. Neste trabalho, as faixas de massa fresca e seca encontradas não condizem com o constatado pelos autores. Entretanto, estão próximas do intervalo de massa seca $\left(0,03\right.$ a $\left.0,4 \mathrm{~kg} \mathrm{~m}^{-2}\right)$ observado por Backes et al. (2010) em grama esmeralda adubada com lodo de esgoto.

Nota-se ainda na Tabela 3 que a Testemunha (sem adubação), diferiu do fertilizante Forth Jardim $^{\circledR}$ em todos os substratos. Já NPK (10-10-10) apresentou resultados estatisticamente iguais a Forth Jardim $^{\circledR}$ com exceção de S2 e S5, sendo essas as médias extremas do tratamento.

Amaral e Castilho (2012) constataram valores de 4,14 $\mathrm{kg} \mathrm{m}^{-2}$ e de $1,37 \mathrm{~kg} \mathrm{~m}^{-2}$ de massa fresca e seca respectivamente em grama batatais adubada com Forth Jardim $^{\circledR}$, e concluíram que esse fertilizante proporcionou melhores qualidades estéticas para o gramado. Valores esses estão muito acima dos encontrados no presente estudo. Já Dinalli et al. (2012) em trabalho com aplicação de fontes de nitrogênio para avaliação de massa seca em grama esmeralda, observou um intervalo de $0,21-0,26 \mathrm{~kg} \mathrm{~m}^{-2}$, não havendo diferença estatística entre os tratamentos, e no presente estudo, apenas os substratos, 1, 2 e 4 sem adubação (Testemunha) se encontram no intervalo proposto.

Conforme já relatado, quanto maior a massa produzida por um gramado, maior o gasto de manutenção, contudo, vale ressaltar, a quantidade e a dificuldade de escoamento da matéria seca gerada do corte das gramas, como estudado por Dourado e Silva (2011), em grama São Carlos (Axonopus affinis e Axonopus compressus). Há altos dispêndios, se forem considerados gastos com mão de obra, operacional, transporte de pessoal e custo de operação do aterro por tonelada de resíduo do gramado (GAZOLA, 2017).

\section{CONCLUSÃO}

Houve resposta da grama esmeralda em função dos fertilizantes e substratos.

O substrato 5 a base de composto orgânico + areia (3:1) apresentou os maiores valores nas análises realizadas.

As adubações realizadas com NPK (10-10-10) e Forth Jardim ${ }^{\circledR}$ apresentaram resultados de clorofila, massa fresca e seca superiores a testemunha (sem adubação). 
O fertilizante Forth Jardim ${ }^{\circledR}$ proporcionou maiores incrementos de massa fresca e seca, e com isso é esperado aumento do custo do corte para manutenção do gramado.

\section{REFERÊNCIAS BIBLIOGRÁFICAS}

ALDAHIR, P. C. F. Composição e uso de campos esportivos. In: BACKES, C.; GODOY, L. J. G.; MATEUS, C. M. D.; SANTOS, A. J. M.; VILLAS BÔAS, R. L.; OLIVEIRA, M. R. Tópicos atuais em gramados III: Botucatu: FEPAF / UNESP - FCA, 2012. cap. 13, p. 175-184.

AMARAL, J. A.; CASTILHO, R. M. M. Fertilizantes comerciais de liberação imediata e controlada na revitalização de grama batatais. Revista Científica Eletrônica de Agronomia, Garça, v. 22, n. 2, p.1-11, 2012. Disponível em: <http://faef.revista.inf.br/imagens_arquivos/arquivos_destaque/uwDnVx4jMbjGY0p_20135-17-18-12-18.pdf>. Acesso em 31 jan. 2018.

BACKES, C. LIMA, C. P.; GODOY, L. J. G.; SANTOS, A. J. M.; VILLAS BÔAS, R. L.; BÜLL, L. T. Produção, acúmulo e exportação de nutrientes em grama esmeralda adubada com lodo de esgoto. Bragantia, Campinas, v. 69, n. 2, p.413-422, 2010. Disponível em: <http://dx.doi.org/10.1590/S0006-87052010000200021>. Acesso em: 20 jan. 2018.

CARRIBEIRO, L. S. Potencial de água no solo e níveis de compactação para o cultivo de grama esmeralda. 2010. 94 f. Dissertação (Mestrado em Agronomia - Irrigação e Drenagem) - Faculdade de Ciências Agronômicas, Universidade Estadual Paulista, Botucatu, 2010. Disponível em: 〈http://hdl.handle.net/11449/93790>. Acesso em: 16 jan. 2018.

CASTILHO, R. M. M.; BARCElOS, J. P. Q.; PONTEL, G. D.; CAROZELli, P. A. Caracterização física de diferentes substratos cultivados com grama esmeralda e sua influência no índice de conteúdo de clorofila. In: SIMPÓSIO DE GRAMADOS - SIGRA, 6, 2012, Botucatu. Anais... Botucatu: UNESP - FCA, 2012. 4 p. CD-ROM

DADOS CLIMÁTICOS - ILHA SOLTEIRA. Canal CLIMA da UNESP Ilha Solteira Área de Hidráulica e Irrigação. Disponível em: <http://clima.feis.unesp.br/recebe_formulario.php〉. Acesso em: 05 jan. 2013.

DIAS, J. A. C.; CASTILHO, R. M. M.; SANTOS, P. L. F. Resposta da grama São Carlos em função do cultivo em diferentes substratos com e sem adubação química. Tecnologia \& Ciência Agropecuária, João Pessoa, v. 9, n. 2, p.27-30, 2015. Disponível em: $<$ http://revistatca.pb.gov.br/edicoes/volume-09-2015/volume-9-numero-2-abril2015/tca9205.pdf >. Acesso em: 21 mai. 2018.

DINALLI, R. P.; BUZETTI, S.; CASTILHO, R. M. M.; GAZOLA, R. N.; CELESTRINO, T. S. Índice de Clorofila na folha de grama esmeralda em função da aplicação de fontes de N. In: SIMPÓSIO DE GRAMADOS - SIGRA, 6, 2012, Botucatu. Anais... Botucatu: UNESP - FCA, 2012. 4 p. CD-ROM 
DINALLI, R. P.; BUZETTI, S.; GAZOLA, R. N.; CASTILHO, R. M. M.; CELESTRINO, T. S.; DUPAS, E.; TEIXEIRA FILHO, M. C. M.; LIMA, R. C. Doses de nitrogênio e aplicação de herbicidas como reguladores de crescimento em grama esmeralda. Semina: Ciências Agrárias, Londrina, v. 36, n. 3, supl. 1, p.1875-1894, 2015. Disponível em: <http://dx.doi.org/10.5433/1679-0359.2015v36n3Supl1p1875>. Acesso em: 17 jan. 2018.

DINALLI, R. P.; BUZETTI, S.; GAZOLA, R. N.; CASTILHO, R. M. M.; TEIXEIRA FILHO, M. C. M.; CELESTRINO, T. S.; DUPAS, E. Nitrogen dose and type of herbicide used for growth regulation on the green coloration intensity of Emerald grass. Ciência Rural, Santa Maria, v. 46, n. 6, p.984-990, 2016. Disponível em: <http://dx.doi.org/10.1590/0103-8478cr20150276>. Acesso em: 17 jan. 2018.

DOURADO, L. C.; SILVA, R. J. P. Estudo sobre impacto de volumes de lixo em aterros proveniente de podas de árvores e jardins. Revista Ciências do Ambiente On-line, Campinas, v. 7, n. 1, p.101-113, 2011. Disponível em: <http://sistemas.ib.unicamp.br/be310/index.php/be310/article/viewFile/278/214〉. Acesso em: 19 jan. 2018.

EMPRESA BRASILEIRA DE PESQUISA AGROPECUÁRIA - EMBR APA. Sistema brasileiro de classificação de solos. Rio de Janeiro: EM B R AP A - CNPS, 2006. 306 p.

FERREIRA, D. F. Sisvar: a Guide for its Bootstrap procedures in multiple comparisons. Ciência e Agrotecnologia, Lavras, v. 38, n. 2, p.109-112, 2014. Disponível em: <http://dx.doi.org/10.1590/S1413-70542014000200001>. Acesso em: 01 fev. 2018.

GAZOLA, R. P. D. Adubação nitrogenada e doses do herbicida glyphosate como regulador de crescimento em grama esmeralda. 2017. 189 f. Tese (Doutorado em Agronomia - Sistemas de produção), Faculdade de Engenharia de Ilha Solteira, Universidade Estadual Paulista, Ilha Solteira, 2017. Disponível em: <http://hdl.handle.net/11449/150612>. Acesso em: 20 jan. 2018.

GODOY, L. J. G.; VILLAS BÔAS, R. L.; BACKES, C. Produção de tapetes de grama Santo Agostinho submetida a doses de nitrogênio. Semina: Ciências Agrárias, Londrina, v. 33, n. 5, p.1703-1716, 2012. Disponível em: <http://dx.doi.org/10.5433/16790359.2012v33n5p1703>. Acesso em: 01 fev. 2018. (a)

GODOY, L. J. G.; BACKES, C.; VILLAS BÔAS, R. L.; SANTOS, A. J. M. Nutrição, adubação e calagem para produção de gramas. Botucatu: Fundação de Estudos e Pesquisas Agrícolas e Florestais, 2012. 146 p. (b)

KÄMPF, A. N. Produção comercial de mudas ornamentais. 2. ed. Guaíba: Agropecuária, 2005. $256 \mathrm{p}$.

KUHN, M. Projeto gramados esportivos Copa do Mundo FIFA 2014. In: MATEUS, C. M. D.; VILLAS BÔAS, R. L.; ANDRADE, T. F.; OLIVEIRA, M. R.; BACKES, C.; SANTOS, A. J. M.; GODOY, L. J. G. Tópicos atuais em gramados IV. Botucatu: FEPAF / UNESP FCA, 2015. cap. 2, p. 23-34. 
LIMA, C. P. BACKES, C.; FERNANDES, D. M; SANTOS, A. J. M.; GODOY, L. J. G.; VILLAS BÔAS, R. L. Uso de índices de reflectância das folhas para avaliar o nível de nitrogênio em grama-bermuda. Ciência Rural, Santa Maria, v. 42, n. 9, p.1568-1574, 2012. Disponível em: <http://dx.doi.org/10.1590/S0103-84782012005000062〉. Acesso em: 02 fev. 2018.

LIMA, C. P. Nutrição, produção e qualidade de tapetes de grama bermuda e esmeralda influenciadas pela adubação nitrogenada. 2009. 144f. Tese (Doutorado em Agronomia Agricultura) - Faculdade de Ciências Agronômicas, Universidade Estadual Paulista, Botucatu, 2009. Disponível em: <http://hdl.handle.net/11449/99974>. Acesso em: 02 fev. 2018.

LIMA, C. P; BACKES, C.; MARQUES, A. J.; FERNANDES, D. M.; VILLAS-BÔAS, R. L.; OLIVEIRA, R. Quantidade de nutrientes extraídos pela grama bermuda e função de doses de nitrogênio. Bioscience Journal, Uberlândia v. 31, n. 5, p.1432-1440, 2015. Disponível em: 〈http://dx.doi.org/10.14393/BJ-v31n5a2015-21967>. Acesso em: 02 fev. 2018.

LORENZI, H. Plantas para jardim no Brasil: herbáceas, arbustivas e trepadeiras. 2. ed. Nova Odessa: Instituto Plantarum, 2015. 1120 p.

MARENCO, R. A.; LOPES, N. F. Fisiologia vegetal: fotossíntese, respiração, relações hídricas e nutrição mineral. 2. ed. Viçosa: Editora UFV, 2007. 469 p.

OLIVEIRA, R. D.; ANDRADE, T. F.; SILVA, T. B. G.; SANTOS, T. F. C.; VILLAS BÔAS, R. L. Intensidade de coloração verde da grama bermuda tifway com diferentes doses de nitrogênio e potássio. In: SIMPÓSIO SOBRE GRAMADOS - SIGRA, 7, 2015, Botucatu. Anais... Botucatu: UNESP - FCA, 2015. 4 p. Disponível em: <http://dx.doi.org/10.12702/VII-SIGRA-a25>. Acesso em: 01 fev. 2018

OLIVEIRA, N. B.; OLIVEIRA, J. F. V.; SANTOS, P. L. F.; GAZOLA, R. P. D.; CASTILHO, R. M. M. Avaliação do estado nutricional de três gramados ornamentais em Ilha Solteira-SP: um estudo de caso. Revista Labverde, São Paulo, v. 9, n. 1, p.96-119, 2018. Disponível em: 〈https://doi.org/10.11606/issn.2179-2275.v9i1p96-119>. Acesso em: 21 mai. 2018

OPTI-SCIENCIES. CCM-200plus: Chlorophyll Content Meter, Proven performance at a great price. Disponível em: 〈https://www.optisci.com/ccm-200.html〉. Acesso em: 17 jan. 2018.

PONTEL, G. D.; CASTILHO, R. M. M.; BOTERO, F. G. Influência de diferentes substratos no teor de clorofila de grama-esmeralda sob condição de estresse hídrico. In: CONGRESSO DE INICIAÇÃO CIENTIFICA DA UNESP - CIC, 23, 2011, Ilha Solteira. Anais... Ilha Solteira: UNESP - FEIS, 2011. 4 p. Disponível em: $<$ http://prope.unesp.br/cic/admin/ver_resumo.php?area=100065\&subarea=19138\&congress o $=32 \& C P F=36681275818$. $>$ Acesso em: 20 mai. 2018. 
SAMPAIO, H. A. Manutenção em gramados ornamentais. In: BACKES, C.; GODOY, L. J. G.; MATEUS, C. M. D.; SANTOS, A. J. M.; VILLAS BÔAS, R. L.; OLIVEIRA, M. R. (Org.). Tópicos atuais em Gramados III. Botucatu: FEPAF / UNESP - FCA, 2012. cap. 15, p. 192-200.

SANTOS, P. L. F.; BARCELOS, J. P. Q.; CASTILHO, R. M. M. Diferentes substratos no desenvolvimento de um gramado ornamental para uso em telhados verdes. Periódico Técnico e Científico Cidades Verdes, Tupã, v. 4, n. 10, p.81-94, 2016. Disponível em: <http://dx.doi.org/10.17271/2317860441020161393>. Acesso em: 01 fev. 2018.

SANTOS, P. L. F.; CASTILHO, R. M. M. Caracterização físico-química de diferentes substratos e sua influência no desenvolvimento da grama esmeralda. Tecnologia \& Ciência Agropecuária, João Pessoa, v. 10, n. 6, p.1-5, 2016. Disponível em: <http://revistatca.pb.gov.br/edicoes/volume-10-2016/v-10-n-6-dezembro-

2016/tca10604.pdf>. Acesso em: 01 fev. 2018.

SANTOS, P. L. F.; CASTILHO, R. M. M. Relação entre teor de clorofila e nitrogênio foliar em grama esmeralda cultivada em substratos. Tecnologia \& Ciência Agropecuária, João Pessoa, v. 9, n. 2, p.51-54, 2015. Disponível em: $<$ http://gestaounificada.pb.gov.br/emepa/publicacoes/revista-tca-emepa/edicoes/volume-092015/volume-9-numero-4-setembro-2015/fitotecnica-crop-science/tca9408.pdf>. Acesso em: 02 fev. 2018.

TAIZ, L.; ZEIGER, E. Fisiologia e desenvolvimento vegetal. 6. ed. Porto Alegre: Artmed, $2017.858 \mathrm{p}$.

ZANON, M. E. Desenvolvimento de grama-esmeralda, grama-bermudas “tifway 419" e “celebration" submetidas a aplicação de reguladores de crescimento. 2015. $58 \mathrm{f}$. Tese (Doutorado em Produção vegetal) - Faculdade de Ciências Agrárias e Veterinárias, Universidade Estadual Paulista, Jaboticabal. 2015. Disponível em: <http://hdl.handle.net/11449/136722>. Acesso em: 18 jan. 2018. 